\title{
Sufijos no apreciativos que sí aprecian: enfoque didáctico para el aula de ELE
}

\author{
DAVID SERRANO-DOLADER \\ Universidad de Zaragoza \\ dserrano@unizar.es
}

\section{Resumen}

Aunque la aplicación de la morfología léxica en la enseñanza y en el aprendizaje de ELE es una parcela poco desarrollada, dentro de ella quizás sea la sufijación apreciativa el ámbito al que más atención se le ha dedicado. No obstante, en este artículo no se estudiarán los derivados tradicionalmente representativos de la sufijación apreciativa entendida en sentido estricto. Partiremos de una consideración amplia del "significado expresivo», y nos centraremos en algunos casos peculiares que deberían integrarse en él para su implementación didáctica en la enseñanza de ELE. Se propone una visión ampliada de la derivación apreciativa en la didáctica de ELE, de modo que en ella deben incluirse casos como: sufijación apreciativa heterocategorial (frenar > frenazo, pecho > pechugona, abusar > abusón, tripa > tripudo, tonto > tontería, ratón > ratonil); sufijación homocategorial con sufijos que suelen quedar excluidos de la derivación apreciativa (sentimental > sentimentaloide, bailar > bailotear, llorar > lloriquear, campeón > campeonísimo). Estos y otros procesos demuestran la marcada tendencia del español a potenciar connotaciones valorativas incluso a partir de sufijos que, en principio, parecerían escasamente proclives a tomar tales sesgos apreciativos (mieditis, titulitis).

\section{Palabras clave}

Didáctica de ELE; significado expresivo; sufijación apreciativa extendida. 


\title{
Non-Affective Suffixes that Do Affect: A Pedagogical Approach to SFL Teaching
}

\begin{abstract}
Lexical morphology remains quite an underexplored area from the perspective of SFL teaching but for one topic: affective suffixation. This paper takes on this topic but with a twist: it examines several cases of suffixation traditionally not included in this category. Stemming from a wider view of the concept of "expressive meaning", this paper focuses on cases such as heterocategorial affective derivation (e.g., frenar > frenazo; pecho > pechugona; abusar > abusón; tripa > tripudo; tonto > tontería; ratón > ratonil) and homocategorial derivation (e.g., sentimental > sentimentaloide; bailar > bailotear; llorar > lloriquear; campeón > campeonísimo). These data show that, contrary to what is expected (e.g. mieditis, titulitis), these suffixes also express affective meanings, and therefore, they should also be included in this category and taught as such in SFL. These results further support the idea that Spanish is a language prone to encode evaluative meanings.
\end{abstract}

\section{Keywords}

SFL didactics; expressive meaning; extended affective suffixation.

Recibido el 11/03/2020

Aceptado el 06/07/2020 


\section{Introducción}

En los últimos años se ha empezado a prestar atención a la morfología léxica del español desde perspectivas didáctico-pedagógicas hasta ahora casi olvidadas. Nos referimos, en concreto, al surgimiento de algunos estudios que pretenden subrayar la importancia de la formación de palabras para el desarrollo del proceso de enseñanza-aprendizaje de léxico, tanto en etapas de educación preuniversitaria del español como lengua materna (Martín Vegas 2018, Gil Laforga 2019) como en el ámbito del español como lengua extranjera (Serrano-Dolader et alii 2009, Serrano-Dolader 2019).

En uno y otro campo, el potenciamiento de la conciencia y de la reflexión metalingüísticas deben ser claves en las que fundamentar el proceso de enseñanza: «La conciencia metalingüística surge de la duda, de la reflexión que en cualquier momento del desarrollo lingüístico nos hacemos acerca del significado, forma y uso de palabras y enunciados» (Martín Vegas 2018: 264). La ampliación del vocabulario se produce a partir de asociaciones de carácter morfológico-semántico:

...a medida que vamos ampliando el conocimiento del mundo, ampliamos nuestro léxico, pero no de forma aislada, sino relacionando conceptos y formas, aprendiendo palabras en relación con otras con las que existen conexiones formales y semánticas. En términos gramaticales, nos referimos a conexiones lexemáticas y afijales, de manera que el aprendizaje del léxico consiste en asimilar nuevos términos a marcos de referencia existentes adheridos por compartir forma, significado o uso (Martín Vegas 2018: 266).

Muchas palabras están ligadas por su morfología, y el conocimiento de su estructura y de su significado facilitará su aprendizaje, su comprensión y su uso (véase Serrano-Dolader 2019). Este reconocimiento implica que el docente debe tomar decisiones pedagógicas y debe seleccionar modelos didácticos a la hora de trabajar con la morfología léxica. Habrá que tomar ciertas decisiones metodológicas que, sin llegar a falsear la realidad de los hechos morfológicos, puedan hacer que la didáctica de la formación de palabras sea más efectiva y fructífera.

Así, en el campo de la enseñanza preuniversitaria -del que no nos ocuparemos aquí- habría que proponer estrategias para acotar, reducir y graduar los contenidos morfológicos abordables en las clases. Es lo que hace, para las etapas de Secundaria y Bachillerato, Gil Laforga (2019). Lo que ahora nos importa de su propuesta es el hecho de que deben tomarse algunas elecciones metodológicas que parecen necesarias de cara a un desarrollo coherente de la didáctica de la formación de palabras. Pongamos un ejemplo a modo de botón de muestra. Aunque la discusión entre los acercamientos sincrónicos y los diacrónicos a la lexicogénesis del español está lejos de haberse cerrado con un acuerdo consensuado entre los morfólogos (véase, por ejemplo, SerranoDolader, 2012), Gil Laforga propone: 
A pesar del indudable interés que tiene el acercamiento diacrónico, si nuestro objetivo es mostrar el modo en que se procesan y generan las unidades léxicas, no parece que este sea el enfoque más adecuado [...]. Por tanto, si el objetivo último del conocimiento de lengua es contribuir a descubrir el modo en que funciona el lenguaje, parece que el camino es la sincronía (Gil Laforga 2019: 51-52).

De la misma forma, en el ámbito de la enseñanza-aprendizaje de ELE, en el campo específico de la creación de palabras (estudiado con amplitud en Serrano-Dolader 2019) puede ser necesario adoptar perspectivas didácticas que se alejen, por lo menos parcialmente, de las canónicamente aceptadas en los estudios descriptivos o en las investigaciones académicas sobre los procesos lexicogenéticos. Para trabajar la sufijación apreciativa en el aula de ELE es didácticamente aconsejable salirse de los estrechos marcos formales que la delimitan en los estudios morfológicos: sin negar que la denominada «sufijación apreciativa», para ser tal, deba ser obligatoriamente homogénea o homocategorial (es decir, que no tiene poder transcategorizador al aplicarse a una base derivativa), creemos que, en el ámbito de ELE, es esta una restricción innecesaria, pedagógicamente no pertinente y didácticamente irrelevante.

El punto de partida es el mismo que ha orientado anteriores trabajos nuestros:

El lexicón mental está organizado de manera asociativa, tanto desde el punto de vista estrictamente conceptual (sinonimias, antonimias, campos semánticos) como desde el punto de vista formal. En este sentido, pretender desarrollar el proceso de enseñanza-aprendizaje de una lengua (y, más específicamente, de su vocabulario) sin atender a los mecanismos de formación de palabras es como intentar desarrollarlo sin hacer mención explícita a otros muchos ámbitos que se han ganado un lugar de honor en la enseñanza del ELE (Serrano-Dolader 2019: 1).

Ese carácter asociativo se fundamenta en aspectos formales, pero también -y con notable potencial- en aspectos semánticos. De este modo, parece plausible que, ante ejemplos como copión, tripudo, ñoñería, cabezón, cutrerío o caciquil, el aprendiz de ELE trace una clara línea asociativa basada en que esas palabras comparten valores apreciativos (despectivos), lo cual resulta didácticamente pertinente. Por el contrario, no parece que el hecho de que algunos de esos derivados hayan sufrido transcategorización de la base (copiar es un verbo pero copión es un nombre) o bien presenten sufijos que habitualmente no se suelen considerar apreciativos (caciqu(e)-il, cutr(e)-erío) le resulte problemático para reconocer el sesgo apreciativo que interrelaciona a todos esos derivados. Sabemos que en las delimitaciones canónicas de la sufijación apreciativa el hecho de que el proceso derivativo deba ser homogéneo (no transcategorizador) es una característica comúnmente aceptada. Sabemos igualmente que, por amplias que sean las listas de sufijos apreciativos propuestas para el español, casos como -il o -erío nunca aparecen en ellas.

En el presente artículo, no vamos a ocuparnos de justificar teóricamente la importancia de atender a la reflexión deductiva e inductiva en la formación de palabras 
en el aula de ELE ni vamos a detenernos en cómo abordar la enseñanza-aprendizaje de la «sufijación apreciativa en sentido estricto» (listillo, perrazo, casucha) en ese ámbito. Para esos aspectos, remitimos al lector a lo ya expuesto en Serrano-Dolader (2019: 280-309).

\section{Sobre la apreciación y los sufijos apreciativos}

La $N G L E$ delimita de este modo la sufijación apreciativa:

Se llaman apreciativos los sufijos que se añaden a numerosos sustantivos y adjetivos, y ocasionalmente también a otras clases de palabras, para expresar tamaño, atenuación, encarecimiento, cercanía, ponderación, cortesía, ironía, menosprecio y otras nociones -no siempre deslindables con facilidad- que caracterizan la valoración afectiva que se hace de las personas, los animales o las cosas: blandengue, calvete, feúcho, fortunón, listillo, pelín, sombrerazo, tipejo, vaquita. En unos casos, el hablante expresa con estas voces alguna cualidad objetiva de lo designado, generalmente el tamaño (banderín, jardincito, portón); en otros muchos manifiesta alguna valoración de carácter exclusivamente subjetivo (madrecita, tontorrón) (NGLE § 9.1a).

Así definida, la sufijación apreciativa entra con pleno derecho en la nómina de procedimientos lingüísticos usados para codificar el denominado «significado expresivo» en español, caracterizado por su carácter subjetivo y evaluativo (véase Porroche Ballesteros 2015). En este sentido, se imponen dos advertencias previas. Por un lado, aunque pueda hablarse de significado expresivo, lo haremos partiendo de una concepción borrosa o no discreta de las categorías lingüísticas, lo cual implica que no siempre es fácil diferenciar entre «significado expresivo» $\mathrm{y}$ «significado descriptivo». Por otro lado, el que una determinada palabra sufijada tenga o no significado expresivo puede depender, en buena medida, del contexto lingüístico y/o del contexto situacional en el que se inserte.

La sufijación apreciativa ofrece espinosos problemas teóricos, que han llevado a algunos lingüistas incluso a proponer que no es prototípicamente ni un caso de sufijación léxica (derivativa) ni un caso de sufijación flexiva sino que ocupa una parcela intermedia entre ambas. En la medida en que no afecten a su proceso de enseñanza-aprendizaje en ELE, este tipo de problemas no serán abordados en el presente trabajo.

Ahora bien, uno de esos problemas «teóricos» a los que acabamos de referirnos sí ha venido afectando -negativamente, en mi opinión- a la enseñanza-aprendizaje de vocabulario en la clase de ELE, más en concreto al posible potencial didáctico de la sufijación apreciativa en ese ámbito. Nos referimos al más que aceptado principio según el cual la sufijación apreciativa no puede modificar la categoría de la base, es decir, que es un proceso homogéneo o no transcategorizador: gato > gatito, tonto > tontorrón, despacio > despacito. Es tal la fuerza de esta restricción morfológica derivativa que, en ocasiones, incluso ha arrastrado a ámbitos cercanos a lo apreciativo a formaciones que 
nada tienen que ver con la expresión de valores expresivos. Por ejemplo, dentro del complejísimo ámbito de los términos de color en español (véase Rello 2009), la propia NGLE puntualiza: «...se asimilan parcialmente a los apreciativos, en tanto que introducen informaciones valorativas, los adjetivos de color que indican tonos aproximados: amarillento, grisáceo, rojizo, verdoso» (NGLE § 9.1e). Si ese tipo de formaciones «se aproxima» a los apreciativos -nótese, por cierto, que el verbo «aproximar» parece abrir la senda no discreta a la que nos referimos más arriba para el tratamiento de la derivación valorativa-, mucho más justificado estará integrar en ella otros procesos derivativos tradicionalmente no considerados como tales. Si la NGLE no ha tenido inconveniente alguno en acercar ese tipo de derivación a la apreciativa es, en buena medida, porque -entre otras cosas- es un caso de derivación homogénea. Nuestra postura es más bien la contraria: el hecho de que, en ocasiones, el proceso derivativo sea transcategorizador no debe ser un inconveniente para que, en el aula de ELE, determinados sufijos puedan ser considerados portadores de valores apreciativos. En el fondo, y si se repasa la definición semántica de «sufijos apreciativos» que ofrece la propia NGLE -y que hemos visto antes-, nuestra propuesta se enmarca, sin calzador alguno, en dicha delimitación.

Si nos basamos en una consideración de la sufijación apreciativa apoyada en el significado (que, creemos, es lo más operativo para el aula de ELE), habrá que tener presentes ciertas peculiaridades que normalmente no son tenidas en cuenta:

1. Habrá determinados sufijos que tengan una doble cara: serán apreciativos en algunos de sus usos y no apreciativos en otros; o incluso serán representantes obvios del carácter borroso o no discreto de la sufijación apreciativa.

2. Ciertos sufijos homogéneos -no cambian la categoría de la base- que habitualmente no se presentan dentro de la sufijación apreciativa deberían integrarse en ella (por lo menos, parcialmente).

3. Algunos sufijos que cambian la categoría de la base traslucen un nítido valor apreciativo (o ese valor se transparenta en la palabra sufijada), razón suficiente como para tenerlos en cuenta al tratar de los procedimientos morfológicos que permiten codificar valores afectivos en español.

4. El estudio de la sufijación apreciativa ha estado muy descompensado en favor de la derivación diminutiva (pequeñito), mientras que la sufijación aumentativa (perrazo) y despectiva (casucha) han sido analizadas de modo menos pormenorizado. Y ello no solo desde el punto de vista lingüístico-filológico sino también en la perspectiva de adquisición de la sufijación apreciativa en primeras o segundas lenguas (véase Dressler y Korecky-Kröll 2015). Precisamente por ello, parece conveniente intentar ampliar las posibilidades de expresión morfológica de esos valores aumentativos y/o despectivos en español.

En Toth (2019) se enumeran una serie de características de los morfemas aumentativos y diminutivos del español, que afectan a la forma, al significado y al uso; y que suponen un verdadero desafío para el aprendiz de ELE. Ante las evidentes dificultades que se asocian a la sufijación apreciativa, no resulta extraño que haya habido reticencias a la hora de incorporar su enseñanza en los niveles más bajos de dominio de español. Así, en el Plan Curricular del Instituto Cervantes (PCIC), hasta el 
nivel $\mathrm{C}$ no se trata el significado no literal en funciones como las utilizadas para mostrar afecto (Es muy viejecito, pero le tengo un gran cariño) o en determinadas expresiones idiomáticas (ser un señorito, ser una mosquita muerta). En nuestra opinión, dada la riqueza y el elevado grado de utilización de este tipo de afijación en español, no resulta justificado retardar hasta niveles avanzados la familiarización del aprendiz de ELE con un mecanismo lexicogenético tan rentable. Por otra parte, la sufijación apreciativa es un procedimiento clave para transmitir valores subjetivos en los mensajes y, en la medida en que la subjetividad está íntimamente ligada al uso del idioma, parece obligado que, desde los niveles iniciales, haya una toma de contacto con la misma por parte de los aprendices. Junto a ello, y es el objetivo último de este artículo, creemos obligado ampliar el concepto de «sufijación apreciativa» para que, a lo largo de los diferentes niveles de enseñanza, los aprendices puedan ir desarrollando las redes asociativas que operan en el lexicón mental de los hablantes.

En lo que sigue, y sin ánimo de exhaustividad, nos centraremos en algunos sufijos que, en diverso grado, ilustran algunas de las cuatro peculiaridades a las que nos hemos referido más arriba. Para la cabal comprensión de nuestra propuesta, reiteramos que dejamos fuera de nuestro estudio la inmensa mayoría de sufijos apreciativos que suelen considerarse canónicamente como tales en la amplísima bibliografía que existe sobre la cuestión.

\section{Un caso emblemático: el sufijo -AZO y su particular galimatías}

Algunos sufijos del español pueden ofrecer una doble cara: usos canónicamente reconocidos como apreciativos junto con otros en los que no parece traslucirse subjetividad alguna y que, como tales, suelen presentarse fuera del ámbito de la derivación apreciativa.

El caso más emblemático es el de -azo, puesto que junto a formaciones claramente apreciativas (perro > perrazo, acento > acentazo), aparece también en otras palabras sin marca de subjetividad (manotazo 'golpe dado con la mano', martillazo 'golpe dado con un martillo'). En uno y otro caso, el sufijo opera sin traer consigo un cambio de categoría en el proceso derivativo (derivación homogénea). Así, el paso de perro a perrazo se incorpora sin problemas a la derivación aumentativa tradicionalmente reconocida como tal ya que la base y el educto son de la misma categoría, característica que para la mayoría de los morfólogos es inexcusable para poder hablar de derivación apreciativa. Por su parte, el proceso derivativo del tipo martillo > martillazo no es un caso de derivación apreciativa-subjetiva y queda catalogado como un proceso de sufijación no apreciativa (en este caso, sin que conlleve tampoco cambio categorial).

No resulta habitual que una determinada palabra en -azo pueda codificar tanto el significado de 'golpe' como el significado más estrictamente 'apreciativo' ya que el mayor uso de uno de esos valores suele tender a bloquear la actualización del otro significado. No obstante, la explicitación de unos u otros tipos de valores está íntimamente ligada a la orientación semántica que marque el contexto. Si es cierto que un ejemplo como martillazo suele indicar valores no apreciativos de 'golpe' (de hecho, 
así suele entenderse esa palabra si aparece descontextualizada), ello no le restringe la posibilidad de ser usada en contextos en los que cobra un valor aumentativo (con la posibilidad de asociar a ellos -o no- ciertos rasgos evaluativos): Chico, tú lo haces todo a lo grande. Has ido a la ferretería y has comprado unos clavos gigantescos y un martillazo que pesa casi un quilo. Pero es que, por su parte, un ejemplo como acentazo (que nos ha servido de ejemplo para subrayar el carácter apreciativo de -azo y que descontextualizado suele interpretarse como portador de subjetividad), resulta que sigue teniendo abierta la posibilidad de aparecer en contextos en los que sea un valor nocional aumentativo (y no apreciativo) el que parezca prevalecer: Soy profe de lengua y me irrita que los alumnos no pongan ya ni un solo acento. Cuando corrijo sus textos, si les falta una tilde, les pongo un acentazo de tres centímetros para que tomen conciencia.

En resumen, en los procesos de sufijación homogénea en los que participa -azo es cierto que pueden desligarse valores apreciativos de otros no apreciativos (que suelen denominarse «nocionales») pero, como acabamos de ilustrar, en el uso contextualizado de las palabras puede producirse una fluctuación entre ambos tipos de valores. Esto viene a subrayar -aun sin salirnos de momento de los casos de derivación homogéneaque la frontera entre sufijación apreciativa y no apreciativa es más fluctuante de lo que pudiera parecer.

El siguiente paso que proponemos -en el marco de una visión de la derivación apreciativa específicamente enfocada a ELE- es superar una de las barreras que han solido marcarse en la identificación de la sufijación apreciativa.

En la descripción canónica de la sufijación apreciativa, es evidente que cualquier morfólogo (o cualquier profesor que lleve a sus clases actividades de reflexión para sus alumnos) subrayará con claridad la inexpugnable frontera que parece separar a un proceso del tipo acento > acentazo de otro del tipo frenar > frenazo. En el primer caso nos encontramos con un ejemplo de derivación apreciativa-aumentativa mientras que en el segundo nos movemos en terrenos externos a la sufijación apreciativa. El hecho de que frenar sea un verbo y frenazo sea un sustantivo es ya razón de peso (o eso ha venido aceptándose) como para excluir a esta derivación heterogénea de la sufijación apreciativa.

Desde el punto de vista de la enseñanza-aprendizaje de ELE, creemos que es necesario romper esa barrera. Para el reconocimiento de valores apreciativos en una determinada palabra sufijada, al aprendiz de ELE le resulta no pertinente el hecho de que el proceso lexicogenético opere cambiando la categoría de la base o lo haga sin cambiarla. El aprendiz debe saber reconocer los valores apreciativos que destacan en las formaciones en -azo de la frase Como le tocó la lotería de Navidad, ahora chulea de chaletazo, cochazo y perrazo; pero exactamente igual debe ser capaz de reconocer el sesgo apreciativo que subyace a las formaciones que aparecen en El nuevo rico destrozó su BMW: iba por la carretera y de repente... pinchazo, frenazo y idirecto al árbol!

Pinchazo o frenazo no aparecen en nómina alguna de sufijación apreciativa pues crean sustantivos a partir de verbos; sin embargo, esas palabras presentan valores intensificadores que están muy próximos a lo apreciativo: designan acciones bruscas o repentinas. Y algo parecido podría decirse de cambiazo (< cambiar) o encontronazo (que, aunque procede del sustantivo encontrón, está asociado al verbo encontrar). 
En didáctica de ELE, la pregunta que debemos plantearnos es: ¿tiene algún sentido mantener en parcelas separadas un caso como coche > cochazo y otro como frenar > frenazo? Desde el punto de vista del significado, parece que la respuesta debe ser negativa.

Por un lado, es obvio -y ya ha quedado dicho- que el cambio o no cambio de categoría en el educto de la regla de formación de palabras no es una característica pertinente para la optimización del proceso de aprendizaje de ELE.

Por otro lado, y como también quedó apuntado, en los casos de sufijación apreciativa canónica los valores apreciativos y los no apreciativos van muchas veces de la mano. Y exactamente esto mismo ocurre en casos como pinchazo o frenazo. Si en estos últimos ejemplos se observa un valor subyacente de 'acción brusca, repentina o contundente' (y la brusquedad o la contundencia parecen conceptos ligables a la apreciación y a la subjetividad), existen también muchos sustantivos denominales en -azo cuyo significado más extendido es precisamente el mismo: cabezazo, cañonazo, tijeretazo, trompetazo... La inmensa mayoría de sustantivos denominales en -azo que se excluyen habitualmente de la derivación apreciativa por codificar un significado -nocional- de 'golpe' presentan, de hecho, una buena carga de apreciación en tanto en cuanto transmiten también una valoración de brusquedad o contundencia en el golpe: nadie hablaría de un martillazo si lo que se ha producido es un involuntario golpecito con el martillo, de la misma manera en la que nadie usaría botellazo para referirse a un golpe causado por la caída accidental de una botella en la mesa. Y, además, a medida que los significados de estos sustantivos van derivando hacia significaciones traslaticias, se pueden ir haciendo más patentes los rasgos evaluativos, que pueden fluctuar (a veces con procesos próximos a la lexicalización) desde las valoraciones positivas (taquillazo 'espectáculo muy rentable por la gran cantidad de público que va a verlo') a las negativas (batacazo 'tremendo e inesperado fracaso', excepto en ciertos países hispanoamericanos en los que significa exactamente lo contrario 'éxito sorpresivo'). Obsérvese además -y es este un nuevo rasgo unificador- que en los derivados tradicionalmente considerados apreciativos-aumentativos también se da esa fluctuación extrema entre la ponderación positiva (gol > golazo) y la negativa (acento > acentazo).

En el aula de ELE -donde debe primar el ámbito del significado por encima de los finos análisis de segmentación morfológica-, todo lo dicho debe conducirnos a tres conclusiones.

En primer lugar, debe trabajarse la diversificación semántica de -azo teniendo en cuenta siempre que la delimitación entre los valores de 'aumentativo', 'golpe' o 'acción brusca o repentina' es a veces clara pero se hace difícil de delimitar en muchos otros casos. Buena parte de los estudios que tratan de mantener como parcelas estancas la derivación apreciativa y la no apreciativa se dejan arrastrar por una tradición que, por lo menos en el ámbito de ELE, puede sembrar más confusión que luz. La gramática descriptiva intenta mantener el juego opositivo y «discreto» entre lo blanco y lo negro -algo que en mi opinión es también contraproducente en el aula de ELE- aunque en ocasiones no le quede otro remedio que reconocer que las fronteras no siempre son 
tajantes (como cuando se asume que ciertos derivados «no son propiamente apreciativos»):

Los derivados en -azo que se refieren a nombres de golpe, sonido o movimiento brusco (cañonazo, flechazo, hachazo, etc.) no son propiamente apreciativos, pero sí lo son las formas homónimas que designan cosas de gran tamaño. El sustantivo cañonazo es, pues, aumentativo si se interpreta como 'cañón enorme', no en cambio si significa 'disparo de cañón'. En muchos de estos casos la interpretación de golpe o movimiento brusco predomina claramente sobre la de tamaño (NGLE § 9.7j).

En segundo lugar, en el aula de ELE tal diversificación es interesante solo en la medida en la que puede ayudar a apoyar el proceso de adquisición del español; lo cual es tanto como decir que, por ejemplo, la discusión sobre la polisemia de un sufijo -azo o la homonimia entre dos posibles sufijos - azo es cuestión de nula operatividad didáctica. De hecho, y como ya subrayamos en la anterior conclusión, los propios límites entre subclases de valores asociados al sufijo -azo son fluctuantes:

Los límites entre los nombres de golpe y los aumentativos son polémicos en unos pocos casos. Se trata de sustantivos en -azo/-aza aparentemente aumentativos que muestran la alteración de género del sustantivo del que se derivan. Así el sustantivo masculino multazo se forma sobre el femenino multa [...]. Puede considerarse aumentativo, pero también nombre de golpe, puesto que esta noción admite diversos usos traslaticios [...] (NGLE § 9.7k).

En tercer lugar, y en este ámbito, formaciones como perrazo, zapatazo o frenazo -con independencia de si sus bases son sustantivas o verbales- conforman un tipo de paradigma que, para el aprendiz de ELE, puede resultar más homogéneo que la manifiesta heterogeneidad que puede rastrear en ellas un concienzudo morfólogo.

\section{Otros apreciables casos de apreciación latente}

\subsection{El sufijo-ÓN}

Cualquier aproximación al sufijo -ón se topa con el problema de que tradicionalmente se han distinguido hasta cuatro subtipos (véanse las sugestivas propuestas para algunos de estos tipos en Gil Laforga 2017): 1) -ón formador de adjetivos denominales (narizón, pechugona); 2) -ón apreciativo que da lugar a aumentativos nominales (peliculón, notición) o adjetivales (simplón, dulzón); 3) -ón que conforma adjetivos deverbales (abusón, vacilón); 4) -ón que configura sustantivos deverbales (empujón, estirón).

Es evidente que las formaciones del tipo 2), sean nominales (novelón, notición, peliculón), sean adjetivales (grandullón, simplón, dulzón), se enmarcan sin problemas dentro de la derivación aumentativa-apreciativa, con toda la carga de subjetividad que 
pueden conllevar. Creemos que, de la misma forma, derivados del tipo 3), como abusón, criticón, copión, dormilón o mirón, presentan valores intensificadores (en la mayoría de los casos, negativos) que, desde la perspectiva del aprendiz de ELE, son semánticamente tan transparentes como los de la serie anterior. La ponderación afectiva existe, exactamente igual, en ambos casos.

Es obvio que hay una clara diferenciación entre ambos tipos: mientras que los primeros son derivados que no cambian la categoría de la base (novela > novelón), los segundos son ejemplos de adjetivaciones deverbales (abusar > abusón); hecho que ha llevado tradicionalmente a hablar de derivación apreciativa para el primer tipo y no hacerlo en el segundo. Una vez más, creemos que resulta más fructífero para el aprendiz de ELE asumir la clara relación entre esas formaciones -basada en compartir valores apreciativos- que la diferenciación marcada porque el proceso lexicogenético sea morfológicamente diverso.

Aunque con menor convicción, también puede defenderse en el ámbito de ELE el posible valor apreciativo-ponderativo de ejemplos del tipo 4), como empujón, resbalón, agarrón, tirón, tropezón. Estos casos comparten con los ejemplos del tipo abusón el presentar un proceso derivativo heterogéneo -en este caso de nominalización deverbal-si bien, al no codificar valores tan claramente calificativos como los de la serie de abusón, su valor apreciativo puede quedar algo más diluido. En todo caso, obsérvese que este tipo de ejemplos (empujón) transparentan ese valor de 'acción brusca o repentina' que ya vimos en el caso de sufijados en -azo del tipo pinchazo o frenazo (igualmente nombres deverbales) y que, como ya queda expuesto, tal connotación está ligada a valoraciones ponderativas que parecen propias de la derivación apreciativa entendida en sentido amplio.

Por otra parte, resulta ilustrativo apuntar que estos derivados en -ón están vinculados con formas nominales deverbales en -(a)da, de modo que no son extraños los dobletes (con diferente extensión geográfica o no): agarrón - agarrada, calentón calentada, empujón - empujada. Tales formaciones son subsumibles, igualmente, dentro de la conceptualización extendida de la sufijación apreciativa que defendemos para el aula de ELE. Obsérvese, por otro lado, que el sufijo denominal -ada, que inicialmente en sus usos de derivación homogénea puede tener valores de 'acción repentina' (estoque > estocada), también puede desarrollar valores peyorativos (gansada, aznarada).

Otro grupo de formaciones en -ón que no siempre se incluyen entre la derivación apreciativa canónica son ejemplos del tipo 1), como cabezón, barrigón, narigón, tetona, pechugona, etc. Es cierto que algunos de esos ejemplos pueden interpretarse sin más como casos de sufijación aumentativa que genera sustantivos -con frecuencia polisémicos- a partir de bases igualmente sustantivas (cabeza > cabezón 'cabeza muy grande' o 'persona que posee una cabeza muy grande'; barriga > barrigón 'barriga muy grande' o 'persona que posee una barriga muy grande'), lo cual sí permite englobarlos sin problemas dentro de la derivación apreciativa (dado su valor ponderativo y su derivación homogénea subyacente); ahora bien, parece claro que la mayoría de estas formaciones pueden presentar también una categorización adjetiva (cabezón 'que tiene la cabeza grande', barrigón 'que tiene la barriga grande'). En este caso, al producirse un cambio de la categoría sustantiva a la adjetiva se estaría violando una de las 
restricciones que suelen reconocerse como caracterizadoras de la derivación apreciativa. A pesar de ello, estas palabras derivadas codifican valores de apreciación y, por lo tanto, dentro de ese ámbito significativo deben ser presentadas en el aula de ELE. Además, todos los sustantivos susceptibles de aparecer como base de estos adjetivos pertenecen a un grupo homogéneo; todos ellos son nombres de posesión inalienable (cabeza, barriga, nariz...), lo cual dota de un carácter regular, productivo y transparente a este tipo de formaciones, características estas que posibilitan una explotación fructífera en el aula de ELE. Por otra parte, y para subrayar la coherencia paradigmática de este tipo de palabras, hay que destacar que en su mayoría codifican los mismos valores apreciativos-despectivos de abundancia o intensidad que los adjetivos deverbales antes analizados (abusón, criticón, copión, dormilón o mirón).

Por último, el español presenta otra serie derivativa en -ón que -partiendo de bases numerales- da lugar a nombres en los que, igualmente, las connotaciones despectivas o irónicas permitirían su integración entre los procesos sufijales apreciativos en el aula de ELE: cuarenta > cuarentón, cincuentón, sesentón, setentón.

En suma, parece mucho más operativo y potencialmente mucho más fructífero para la enseñanza-aprendizaje del léxico en ELE subrayar la ligazón asociativa de carácter apreciativo que relaciona a todas estas formaciones en -ón que intentar implementar en el aula posibles divergencias morfológicas subyacentes entre subtipos de formaciones (narizón $\neq$ peliculón $\neq$ abusón $\neq$ empujón).

\subsection{El sufijo -UDO}

Salvo casos excepcionales (suertudo, cojonudo), la gran mayoría de los adjetivos denominales en -udo marcan con nitidez valoración apreciativa despectiva: barrigudo, cabezudo, tripudo, barbudo, peludo, etc. Una vez más, nos encontramos con que, al producirse cambio de categoría entre la base (sustantiva) y el derivado (adjetivo), no suelen incluirse en el elenco de la sufijación apreciativa estricta. Esta serie conforma un grupo -bien representado en español y potencialmente productivo- de formaciones de valor homogéneo: caracterizan negativamente a las personas o a los animales que destacan por el tamaño, el exceso, la desproporción o la abundancia de alguna parte de su cuerpo. Y, una vez más, creemos que en la didáctica de ELE estos derivados deberían integrarse en el ámbito de la expresión sufijal de valoraciones apreciativas.

Resulta relevante que presenten exactamente el mismo valor ponderativo descalificador que ciertos derivados -también denominales- en -ón antes estudiados: cabezón = cabezudo, barrigona $=$ barriguda, tetona $=$ tetuda . Estamos, de hecho, ante un mismo tipo de proceso: creación de adjetivos denominales de valor despectivo que presentan, de manera regular y transparente, una configuración de valores apreciativos que, para el aprendiz de ELE, puede resultar fácil de identificar.

Es importante subrayar este tipo de relaciones entre las diversas formaciones que estamos estudiando. No nos hallamos ante piezas léxicas aisladas que presenten valores apreciativos intrínsecos (como pueden tenerlo palabras no complejas del tipo feo, tonto o idiota) sino ante palabras derivadas cuya carga afectiva proviene de la aplicación de determinados sufijos sobre una base de derivación. En el caso de feo o de tonto la 
morfología léxica nada puede aportar para la facilitación de su adquisición por parte del aprendiz de ELE, pero en casos como cabezón o cabezudo la morfología léxica aporta una regularidad y un potencial de productividad que pueden favorecer al aprendiz tanto su adquisición como su uso. No olvidemos que el lexicón mental no se estructura de modo caótico y libre sino que está ligado por relaciones paradigmáticas, de regularidad y asociativas en las que la morfología léxica sí tiene mucho que decir.

Es cierto, no obstante, que en ocasiones el sesgo apreciativo específico que tome una determinada formación sufijada puede provenir de ciertas consideraciones externas al proceso derivativo en sí. Así, el hecho de que una palabra como cojonUDO (< cojón) tenga un valor ponderativo positivo en español vulgar frente a otra como coñAZO (<coño), que está cargada de valor ponderativo negativo, es ajeno tanto al valor denotativo de sus bases de derivación como a la diversificación en la selección sufijal -sea del sufijo -udo (cojonudo), sea del sufijo -azo (coñazo)-. En este sentido, es conveniente recordar que también son numerosos los ejemplos de derivados a través de sufijación apreciativa estricta que desarrollan un proceso de lexicalización que incluso trae consigo la pérdida de los valores apreciativos subyacentes a esas palabras: tornillo, manzanilla, pajarita, sillín, telón, camisón, islote, sablazo.

Seguimos defendiendo que los procesos de derivación léxica (muy especialmente aquellos más regulares, más transparentes y más productivos) pueden ser de inestimable ayuda para favorecer la adquisición de vocabulario en ELE y que, en consecuencia, la consideración extendida que venimos defendiendo para la «derivación apreciativa» en ELE puede resultar fructífera en su implementación en el aula.

\subsection{El sufijo -ERÍA}

No es este el momento de discutir el carácter, bien de sufijo, bien de complejo sufijal, de -ería en español. En todo caso, habitualmente no forma parte de la nómina de sufijos apreciativos en la medida en que puede dar lugar a nombres con claro contenido nocional y que, además, suelen conformar grupos semánticamente homogéneos: nombres de cualidad o condición (tontería, glotonería, simplonería), nombres de establecimiento (chocolatería, cervecería, camisería) o nombres de grupo (cubertería, grifería, mantelería).

El educto resultante de la regla de adjunción del sufijo -ería no posee carácter valorativo alguno en los casos en los que se genera un significado de establecimiento (cervecería) o de grupo (mantelería). Ahora bien, la inmensa mayoría de derivados en -ería dentro del grupo de 'cualidad o condición' son del tipo: simplonería, cabezonería, bobería, ñoñería, guarrería. Estos ejemplos sí poseen un marcado valor apreciativo (despectivo) y, en el aula de ELE, deben asociarse con claridad a los procesos sufijales de valor apreciativo tradicionales. Una vez más, el hecho de que en la mayoría de estos casos la derivación pueda ser heterogénea (ñoño > ñoñería) es pertinente tal vez para su exclusión de la sufijación apreciativa con criterios morfológicos estrictos pero no impide que este tipo de formaciones deba integrarse en una concepción ampliada de la sufijación apreciativa con fines didácticos en ELE. 
No obstante, en estos casos se da una circunstancia que, por lo menos, debe ser tenida en cuenta (por el docente y por el aprendiz de ELE). Las bases que corresponden a los derivados antes citados son: simplón, cabezón, bobo, ñoño, pedante, guarro. Todas esas bases de derivación poseen por sí mismas una carga apreciativa despectiva: sea porque ya presentan un sufijo valorativo despectivo (caso de simplón o de cabezón), sea porque la palabra en sí configura un significado marcadamente negativo (caso de pedante). Al morfólogo se le debe plantear la duda de si el carácter peyorativo de simplonería, cabezonería, o pedantería procede, en consecuencia, de la aplicación del sufijo -ería o simplemente del hecho de que la base de derivación desde la cual se conforma el significado de 'cualidad o condición' ya es portadora previamente de esa valoración peyorativa. Esta es, no obstante y así planteada, una cuestión de escaso interés (y nula operatividad didáctica) en el aula de ELE, donde lo que debe primar es el hecho de que los eductos ofrecen valores despectivos y no la pregunta -casi bizantina en este marco didáctico- de si glotonería tiene valor negativo porque lo tiene ya glotón, o porque lo aporta el sufijo -ería, o porque tanto el significado de la base como el sufijo coadyuvan a generar ese significado negativo del educto.

Como en este trabajo estamos planteando cuestiones atingentes a la sufijación apreciativa en sentido lato (no tanto a los valores apreciativos en sí de las palabras), hay dos hechos que sí pueden apoyar nuestra postura de centrar la atención en el sufijo y en los valores a los que parece dar lugar. Por una parte, hay también algunas formaciones en -ería que se cargan de valores peyorativos que no están presentes en las bases de derivación correspondientes: niño > niñería, político > politiquería, lo cual favorecería la consideración de -ería como un sufijo que sí puede aportar valoración negativa. Por otra parte, son muy escasas las formaciones en -ería que no llevan claramente asociados valores negativos (galantería, coquetería). De ambas observaciones, podemos deducir una formulación que puede resultar didácticamente pertinente en ELE en la medida en que puede servir de ayuda al aprendiz cuando se confronte con derivados en -ería en español: el sufijo -ería -cuando aporta valor genérico de 'cualidad o condición'- suele seleccionar bases de significado despectivo (de donde obviamente se deduce que la mayoría de formaciones de 'cualidad o condición' en -ería presentarán dicho valor despectivo).

Obsérvese, por último, que el sufijo -ería puede alternar, de manera asistemática, con otros sufijos nominalizadores dando lugar al mismo tipo de significado despectivo: tontería - tontada, bobería - bobada, ñonería - ñonez, sosería - sosez. Este hecho, dada la importancia que concedemos a las asociaciones morfológicas y a las relaciones paradigmáticas en la enseñanza del léxico en ELE, puede resultar interesante y pertinente para el aprendiz.

\subsection{El sufijo - ERÍO}

Tampoco el sufijo o complejo sufijal -erío suele formar parte de la nómina de sufijos apreciativos puesto que tiende a configurar sustantivos que indican 'grupo, conjunto o colectivo', en los que no se destacan notas subjetivas: averío ('conjunto de aves'), graderío, mujerío, mocerío, monjerío, etc. 
Sin embargo, no son pocas las formaciones así creadas en las que sí se observan connotaciones irónicas-despectivas o matices subjetivos de displicencia: rojerío, cutrerío, facherío. Y, a diferencia de lo que ocurre cuando el valor subyacente es meramente el de 'conjunto o colectivo' -sin notas de apreciación-, este sí parece ser un proceso derivativo que, en español coloquial especialmente, puede presentar un cierto grado de productividad: Madrid se ha convertido hoy en un sitio repleto de rojerío, puterío, pobrerío y pijerío. Es significativo que también en Hispanoamérica el sufijo -erío tenga un marcado potencial productivo para la formación de nombres de grupo con matices de valoración negativa (piberío, viejerío, genterío, mujererío), potencial que se extiende incluso para la configuración -en lengua coloquial de zonas hispanoamericanas- de colectivos con connotación apreciativa-irónica no referidos a personas: papelerío, fiesterío, lucerío, bicherío.

Es cierto que, como ocurría con algunos de los sufijos estudiados antes, esa valoración negativa puede derivarse -en todo o en parte- del propio significado de la base de derivación y no (solo) de la presencia del sufijo -erío: rojo > rojerío, facha > facherío, cutre > cutrerío. Sin embargo, el potencial creativo del sufijo para generar palabras con valores negativos parece razón de peso para que, en el ámbito de la enseñanza-aprendizaje de ELE, este proceso derivacional deba ser tenido en cuenta al tratar de los procedimientos lexicogenéticos de matiz apreciativo en español. El hecho de que la valoración negativa de formaciones coloquiales como papelerío, fiesterío o lucerío obviamente no pueda derivarse del significado -no valorativo- de la base (papel, fiesta, luz) implica que el sufijo -erío sí presenta un cierto sesgo apreciativo-negativo en español. En este sentido, sugerimos también su inclusión dentro de la consideración extendida de la sufijación apreciativa para el aula de ELE.

\subsection{El sufijo -OIDE}

El sufijo -oide forma, a partir de nombres, adjetivos que pueden denotar, sea 'relación con', sea 'semejanza'. Se ha especializado en algunos campos: se usa frecuentemente a partir de bases nominales en el ámbito médico-científico (reumatoide, difteroide, esquizoide), y asimismo suele hacer referencia adjetiva específica a formas geométricas (esferoide, romboide, trapezoide) o usarse en el ámbito de la química (alcaloide, metaloide, cristaloide). Es claro que en tales ámbitos de especialización -por las propias pautas que rigen en el seno del lenguaje científico- ni -oide ni los derivados con él creados presentan carga subjetiva alguna.

Sin embargo, en el lenguaje común sí es frecuente que los adjetivos derivados en -oide presenten matices descalificativos: actitudes comunistoides, mente locoide, aplausos sentimentaloides, crimen gansteroide. Es cierto que tales valores descalificativos pueden venir dados, sea porque la base de derivación ya los presenta (loco, gánster), sea porque la calificación adjetival incide sobre un sustantivo que ofrece en sí valores negativos (crimen). En todo caso, este sufijo -oide tiene también una cierta operatividad para crear neologismos en español que presentan carácter de semejanza (por ello suelen ser equivalentes a formaciones prefijadas con pseudo-) marcada de una cierta descalificación: chaplinoide, genialoide, extranjeroide, eruditoide, intelectualoide, 
etc. De este modo, y como lo realmente operativo en la enseñanza de ELE no es tanto el etiquetamiento de valores en los sufijos cuanto su operatividad codificadora en la cadena comunicativa, creemos que -por más que, de nuevo, nos encontremos ante un proceso derivativo que puede cambiar la categoría de la base- resulta fructífero incluir este tipo de creación lexicogenética al tratar la carga subjetiva que la sufijación puede traer consigo en español.

\subsection{El sufijo $-I L$}

El sufijo adjetivador denominal -il puede dar lugar a formaciones sin valor apreciativo alguno (estudiantil, varonil, mercantil): sea en usos relacionales (enfermedad infantil), sea en usos calificativos (reacción infantil).

No obstante, es frecuente que los adjetivos en -il se carguen de connotaciones apreciativas despectivas: masa borreguil, usura ratonil, suciedad cerdil, comportamiento caciquil, pleitesía servil, método gansteril. Obsérvese que en estos casos puede no quedar claro si el valor apreciativo despectivo procede, en realidad, del sufijo en sí o más bien del significado de la palabra base (borrego, ratón, cerdo, cacique, siervo, gánster) o de la contextualización en la que aparece la palabra en cuestión, al calificar a un sustantivo que puede poseer ya matices negativos (masa, usura, suciedad, pleitesía). En este sentido, es muy frecuente que se combinen ambas posibilidades, es decir, que tanto el adjetivo de base como el sustantivo al que acompaña tengan cargas potencialmente despectivas: usura ratonil, suciedad cerdil. Si bien es cierto que no podemos calificar al sufijo -il como un derivativo claramente apreciativo, hechos tan significativos como los que hemos destacado nos llevan a considerar (exactamente por las mismas razones que propusimos para el sufijo -oide) que este comportamiento en el discurso hace que, para el aprendiz de ELE, pueda resultar conveniente subrayar esta peculiaridad si se trata de reflexionar sobre el potencial apreciativo de la sufijación en español.

\section{Dos casos más para rizar el rizo: corr-ETEAR y gord-ÍSIMO}

\subsection{Sobre verbos deverbales (y no deverbales) de valor apreciativo}

No es muy frecuente en español la creación de verbos a partir de otros verbos, es decir, la generación de verbos deverbales. No pretendemos aquí desarrollar un análisis de los mismos (véase Rifón Sánchez 1998) sino simplemente dejar constancia de su potencial apreciativo.

Salvo algunas excepciones (apretujar, mascullar, escobazar, rasguñar), este proceso lexicogenético es casi exclusivo de ciertas variantes de derivación en -ear: -etear (corretear, toquetear), -otear (pisotear, bailotear), -orrear (andorrear, chismorrear), -urrear (canturrear), -(u/i)quear (besuquear, lloriquear), -ejear (forcejear), etc. La mayoría de estos verbos deverbales creados a través de sufijos complejos (o interfijos + -ear) se caracterizan por desarrollar valores nocionales 
iterativos, repetitivos o frecuentativos (por lo que para muchos morfólogos no son, en sentido estricto, sufijados apreciativos). Pero pueden conllevar matices expresivos de diversos tipos (atenuadores, cariñosos, despreciativos), lo que permitiría su tratamiento en el seno de la apreciación expresada morfológicamente. De hecho, algunos estudiosos han establecido un fuerte correlato explícito entre la sufijación apreciativa nominal y esta sufijación «apreciativa» verbal:

[En los verbos deverbales] la dimensión aspectual de intensidad de la acción se puede comparar con la dimensión nominal que opone el diminutivo y el aumentativo; en la dimensión aspectual verbal lo que aumenta o disminuye es la intensidad con que se realiza la acción, mientras que en la nominal lo que aumenta o disminuye es el tamaño u otros rasgos del objeto. [...] De la misma manera que en la apreciación nominal a los valores aumentativo y diminutivo se les pueden añadir los valores nocionales positivo y negativo o estos presentarse de forma independiente; en la apreciación verbal a los valores aspectuales intensivo y atenuativo se les pueden añadir connotaciones positivas o negativas aunque, en el caso de los verbos, el único valor que casi con exclusividad se presenta es el negativo (mascujar 'mascar mal', bailotear 'bailar mucho y sin gracia') (Rifón Sánchez 1998: 220).

No deja de resultar paradójico que, a pesar de no implicar cambio de categoría, estos sufijos de matiz frecuentativo no se agrupen tradicionalmente -salvo excepciones- con los apreciativos ya que, indudablemente, añaden connotaciones expresivas muy marcadas. Los valores ponderativos que se expresan con muchos de estos verbos los aproximan a la sufijación apreciativa, de manera que el docente de ELE dispone de la opción didáctica de abordar este tipo peculiar de creación verbal en el ámbito de la sufijación apreciativa.

Por otra parte, aunque no podamos centrarnos en ello debido a los límites de este artículo, sí queremos dejar apuntado que existen también otros procesos de derivación verbal, en este caso transcategorizadora, que también podrían apuntar hacia la codificación de valores subjetivos y evaluativos de interés en la clase de ELE. Nos limitamos, por los motivos apuntados, a poner un solo ejemplo de esta derivación verbal con connotaciones apreciativas; caso especialmente significativo porque parece marcar una tendencia lexicogenética regularizable $\mathrm{y}$, por ende, de aprovechamiento en la enseñanza de ELE:

... en el caso de -ear cuando se combina con nombres propios para formar neologismos verbales, generalmente $a d$ hoc, muy presentes en los medios de comunicación, únicamente se actualiza una carga semántica disfemística. [...] De entre el conjunto de acciones características de cualquier persona, sea un personaje público o no, se actualizan de forma exclusiva los rasgos de carácter o modos de actuación tenidos por vituperables. Esto se comprueba en ejemplos como aznarear, pujolear, etc. La tendencia se subraya, además, en construcciones también de sentido disfemístico, con el morfema -izar, como aznarizar (García Platero 2019: 66). 


\subsection{Un caso en "grado extremo»: el sufijo -ÍSIMO}

De manera semejante a lo que ocurre con los verbos a los que acabamos de referirnos, tampoco se agrupan tradicionalmente con la derivación apreciativa -a pesar de no conllevar cambio de categoría y añadir un claro valor expresivo- los adjetivos en -ísimo.

Como sabemos, -ísimo da lugar a los denominados adjetivos superlativos absolutos, que pueden interpretarse como adjetivos elativos o de grado extremo con claros valores expresivos: inteligentísimo, oscurísimo, tristísimo. Para muchos morfólogos, no es propiamente sufijo apreciativo ya que, al codificar la expresión del grado adjetival, se suele encuadrar entre las variables de flexión y, en consecuencia, cae fuera del ámbito de la sufijación derivativa o léxica. Como marca de grado que es, en principio parece poder afectar a todo tipo de adjetivos calificativos, lo que lo convierte en representante de un proceso que presenta una enorme productividad en español y un elevado grado de regularidad en la codificación de los contenidos que configura.

Su innegable orientación semántica apreciativa ya justificaría su inclusión entre los sufijos apreciativos en el aula de ELE pero es que, además, y como queda dicho, representa un proceso enormemente productivo y regular. Precisamente estas dos características, junto con la transparencia semántica del educto -que también se da en estos procesos de creación de adjetivos en -ísimo-, son las que deben delimitar a aquellos procesos lexicogenéticos que, con mayor eficacia y beneficio, pueden implementarse explícitamente en la clase de ELE. La adjetivación elativa en -ísimo es quizás uno de los procesos más prototípicamente susceptibles de un eficaz y fructífero tratamiento reflexivo en el aula. Obvio es decir que, para el aprendiz de ELE, la posible caracterización morfológica de este sufijo, sea como flexivo, sea como derivativo, resulta asunto baladí y -lo que es más importante- de nula trascendencia para su proceso de aprendizaje.

El potencial expresivo-apreciativo del sufijo ha favorecido que, de manera teóricamente sorprendente, se haya ido extendiendo a bases sustantivas dando lugar a formaciones que poseen valores expresivos, con connotaciones enfáticas, burlescas, etc.: campeonísimo, generalísimo, finalísima, nietísimo, hermanísimo, etc. En esta línea, es incluso un procedimiento susceptible de ponerse en marcha para la creación de neologismos a los que queremos dotar de una evidente carga ponderativa: Lo de esos grandes almacenes no son rebajas sino rebajísimas. Negar el carácter morfológico derivativo (y no flexivo) y su más que clara significación apreciativa no tiene ya -sobre todo a la vista de este último tipo de ejemplos denominales- asidero alguno y, en consecuencia, su encuadre dentro de la derivación apreciativa está más que justificado y es más que recomendable en el aula de ELE.

\section{Conclusiones}

Como quedó anotado al principio, no hemos pretendido hacer un repaso exhaustivo de todos los sufijos no apreciativos que sí aprecian sino centrarnos en algunas significativas muestras para apoyar su inclusión dentro de un concepto 
ampliado de sufijación apreciativa que pueda tener operatividad didáctica en la clase de ELE. Hay, pues, más casos que aquí no hemos tratado sistemáticamente. Entre ellos, destacamos dos ámbitos. Por un lado, ciertos adjetivos denominales en -oso que denotan la presencia abundante de algo con connotaciones valorativas ( $b a b a>b a b o s o$, ruido > ruidoso) y que son semánticamente muy semejantes a adjetivos valorativos deadjetivales (elegantoso, intelectualoso, modernoso) o deverbales (buscoso, hostigoso, preguntoso) muy frecuentes en español americano. Por otro lado, ciertas formaciones de uso prioritario en el español coloquial o juvenil: sustantivos y/o adjetivos deverbales en -ica (acusica, quejica, llorica), nombres deverbales en -ata (fregata 'camarero') y nombres deadjetivales en -ales (rubiales, frescales) o en -eras (guaperas, golferas).

No podemos obviar tampoco la marcada tendencia del español a potenciar connotaciones valorativas incluso a partir de sufijos que, en principio, parecerían escasamente proclives a tomar sesgos apreciativos. Quizás el caso más llamativo sea el de un sufijo técnico-científico como -itis ('inflamación') que, junto a derivados cultos del tipo amigdalitis, apendicitis o bronquitis, va dando lugar a múltiples creaciones con claro sentido devaluativo: mieditis, titulitis, discursitis, gandulitis... Este tipo de casos, que entran de lleno ya en la posibilidad de la utilización lúdica de la morfología léxica, ha quedado fuera de nuestras reflexiones si bien resulta de interés para los niveles más avanzados de la enseñanza de ELE.

\section{Referencias bibliográficas}

DRESSLER, W. U. y K. KORECKY-KRÖLL (2015). «Evaluative Morphology and Language Acquisition». En: N. GRANDI y L. KÖRTVÉLYESSY (eds.). Edinburgh Handbook of Evaluative Morphology. Edinburgh: Edinburgh University Press: 134-141.

GARCÍA PLATERO, J. M. (2019). «La afijación apreciativa y su tratamiento lexicográfico». En: A. ADELSTEIN et alii (eds.): Clases y categorías en la formación de palabras en español. Leipzig: Leipziger Universitätsverlag: 53-69.

GIL LAFORGA, I. (2017). «Los límites de la sufijación apreciativa: las formaciones con el sufijo -ó». En: J. PENA (ed.). Procesos morfológicos: zonas de interferencia (Verba. Anexo 76). Santiago de Compostela: Universidade de Santiago de Compostela: 191207.

GIL LAFORGA, I. (2019). «El análisis morfológico en el aula. Perspectiva, contenidos y actividades». ReGrOC (Revista de Gramática Orientada a las Competencias), 2/1: 4366.

INSTITUTO CERVANTES (2007). Plan curricular del Instituto Cervantes (Niveles de referencia para el español) (PCIC). Madrid: Instituto Cervantes - Edelsa, 3 vols. <http://cvc.cervantes.es/Ensenanza/biblioteca_ele/plan_curricular/default.htm.

MARTÍN VEGAS, R. A. (2018). «Modelos de aprendizaje léxico basados en la morfología derivativa». Rilce (Revista de Filología Hispánica), 34/1: 262-285.

PORROCHE BALLESTEROS, M. (2015). «Sobre la manifestación del significado expresivo en español». En: D. SERRANO-DOLADER et alii (eds.). Aspectos de la 
subjetividad en el lenguaje. Zaragoza: Institución «Fernando el Católico» (C.S.I.C.): 187-205.

REAL ACADEMIA ESPAÑOLAy ASOCIACIÓN DE ACADEMIAS DE LA LENGUA ESPAÑOLA (2009). Nueva gramática de la lengua española (NGLE). Madrid: Espasa Libros.

RELLO, L. (2009). «Términos de color en español: semántica, morfología y análisis lexicográfico. Definiciones y matices semánticos de sus afijos». Diálogo de la Lengua (Revista de filología y lingüística españolas), I: 79-164.

RIFÓN SÁNCHEZ, A. (1998). «La derivación verbal apreciativa en español». Estudios de Lingüística. Universidad de Alicante (E.L.U.A.), 12: 211-226.

SERRANO-DOLADER, D. et alii (eds.) (2009). Morfología y español como lengua extranjera (E/LE). Zaragoza: Prensas Universitarias de Zaragoza (PUZ).

SERRANO-DOLADER. D. (2012). "Tensiones entre sincronía y diacronía en la descripción de la morfología léxica del español: el caso de la Nueva Gramática de la Lengua Española (NGLE)». En: M. Campos Souto et alii (eds.). «Assi como es de suso dicho». Estudios de morfología y léxico en homenaje a Jesús Pena. San Millán de la Cogolla. Cilengua: 485-498.

SERRANO-DOLADER, D. (2019). Formación de palabras y enseñanza del español LE/L2. London / New York: Routledge.

TOTH, P. D. (2019). «Morfología». En: Muñoz-Basols et alii (eds.). The Routledge Handbook of Spanish Language Teaching: metodologías, contextos y recursos para la enseñanza del español L2. London / New York: Routledge: 301-315. 